\title{
RELATIONSHIP BETWEEN FUNCTIONAL DISABILITY AND BELIEFS AMONG NURSES WITH LOW BACK PAIN
}

Hameeda Dharani ${ }^{* 1}$, Soni $S^{2}$.

${ }^{* 1}$ Post graduate Student, Department of Physiotherapy, Ramaiah Medical College and Hospitals, Bangalore, Karnataka, India.

${ }^{2}$ Associate Professor, Department of Physiotherapy, Ramaiah Medical College and Hospitals, Bangalore, Karnataka, India.

\section{ABSTRACT}

Background: Low back pain (LBP) is a significant problem among nurses. The consequence of LBP is decreased level of daily activities and work productivity. LBP has been linked to biopsychosocial factors. Among them, beliefs about the pain are crucial as they have an effect on recovery process. There is paucity of evidence for understanding the relationship between beliefs and functional disability about LBP. The purpose of the present study was to investigate the co-relation between functional disability and beliefs among nurses with LBP.

Materials and Methods: A cross sectional study was conducted. One forty participants fulfilled the inclusion criteria and self administered questionnaires were given to them. The functional disability was assessed using Oswestry Disability index (ODI) and beliefs related to their back pain were assessed using Back Beliefs Questionnaire (BBQ).

Results: The median score of nurses on ODI was $20 \%$ indicating minimal disability. For the BBQ, the median score was 27 which indicate positive beliefs of nurses towards LBP. Spearman's rho test indicated very weak negative correlation between $\mathrm{ODI}$ and $\mathrm{BBQ}$ scores with a $\mathrm{p}$ value $<0.05$.

Conclusion: The study suggests that there was minimal disability among nurses and also they demonstrated moderately positive beliefs towards LBP. The beliefs of nurses did not influence their level of function.

KEY WORDS: Low back pain, nurses, functional disability, beliefs, ODI, BBQ.

Address for correspondence: Hameeda Dharani, Post graduate Student, Department of Physiotherapy, Ramaiah Medical College and Hospitals, Bangalore- 560054, Karnataka, India.

Email: hameedadharani52@gmail.com

\section{Access this Article online}

Quick Response code

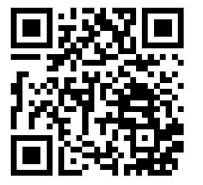

DOI: $10.16965 /$ ijpr.2017.182
International Journal of Physiotherapy and Research

ISSN 2321- 1822

www.ijmhr.org/ijpr.html

Received: 05-06-2017

Peer Review: 06-06-2017

Accepted: 19-06-2017

Published (0): 11-08-2017

Revised: None

Published (P): 11-08-2017

\section{INTRODUCTION}

Work-related musculoskeletal disorder (WMSD) is an emerging problem in our society and second largest cause of short-term work related disability. Health care profession is at high risk for WMSDs. Among all the health care professionals (HCPs), nurses have highest prevalence of WMSDs with major complaint of LBP [1]. Non - specific LBP is defined as "pain between the 12 th rib and the inferior gluteal folds, with or without leg pain and present in the absence of any specific pathology" [2]. The prevalence of LBP among Indian nurses is $53.4 \%$ and this is predisposed by the nature of their work. Twisting, bending, handling an excessive number of patients, manual material handling [3], working in awkward positions and lack of lifting aids forces the nurses to strain during shifting of patients leading to LBP [1].

In addition to this, psychosocial predictors such 
as beliefs about LBP, psychological distress and coping behaviours contribute to the development of LBP [4]. Nurses in India are under enormous stress and have economical constraints which might have an effect on their beliefs related to LBP [5].

The consequence of LBP is functional disability, loss of work productivity and absenteeism $[6,7]$. People who experience non-specific LBP report impaired ability to perform daily activities. Dawson et al. (2007) in a systematic review found that there is low level of evidence related to efficacy of workplace interventions in prevention of LBP in nurses [8].

LBP is best understood from biopsychosocial viewpoint, which recognizes the important interactions between biological, psychological and social aspect of a person's experience of pain [9]. These three aspects are important as they have an impact on an individual's pain and development of disability. Beliefs and attitudes associated with the experience of LBP and its consequences influences the self management behaviors [6]. The biopsychosocial model illustrates the mechanism of how fear of movement/ (re)injury contributes to maintenance of chronic pain disability. For the management of chronic LBP, this model focuses on effective self-management [10].

Factors such as culture, place of work, education, personal experience of LBP and sequelae of LBP such as disability affect the back pain beliefs. It has been shown that higher levels of pain and disability are associated with negative beliefs whereas positive beliefs are associated with recovery process [6]. Therefore, belief system of an individual is very important which needs to be addressed during intervention of LBP. In a cross-sectional study, it was found that majority of nurses credited doctors and physiotherapists as main source of knowledge because they received some information about LBP in the past [4]. This lack of knowledge might affect the back pain beliefs and lead to chronicity of LBP among nurses. Moderate level of evidence is present on back pain beliefs affecting the pain behaviour but the level of disability caused by LBP has not been specifically investigated in Indian nurses. Thus individuals who believe that activity may do further damage to their back are likely to rest and become functionally inactive [11]. There is limited information and literature to understand the relationship between beliefs about LBP and functional disability in nurses. As LBP is a significant problem among nurses, interventions should not only focus on physical factors that cause pain but biopsychosocial aspect of pain should also be considered. Therefore, understanding the relationship between beliefs and functional disability is necessary as any intervention planned cannot be effective unless it addresses this issue. Hence, the aim of the study is to find out relationship between functional disability and beliefs among nurses with LBP.

\section{MATERIALS AND METHODS}

A cross-sectional study was conducted from December 2016 to February 2017. Ethical clearance was obtained from the ethical committee of Ramaiah Medical College and Hospitals, Bangalore. Permission was taken from the hospital authority to conduct the study. The list of names of the nurses was taken from the Nursing Superintendent which contained 889 names. 480 subjects were randomly selected for screening. Simple random sampling was done to eliminate the bias and give equal chance to every person in the population for being selected for the study.

Informed consent was obtained from each participant prior to screening. A screening tool was designed by the researcher which included questions about the demographic as well as professional specifications. After screening all the participants, data was analyzed for those who were aged between $25-45$ years, had back pain without neurological symptoms and had no history of fall or trauma. Participants not willing to provide informed consent, who had non mechanical reasons for back pain, had neurological symptoms, had vertebral fractures or had undergone back surgery were excluded. Participants with LBP, fulfilling the inclusion and exclusion criteria were asked to fill ODI and BBQ. The ODI questionnaire measures pain related functional disability of an individual. The scoring represents the degree of disability relating 
to scores of the questionnaire. The internal consistency of ODI ranges from Cronbach $\alpha=.71$ to .87 and the test - retest reliability ranges from 0.83 to 0.99 which is high [12]. The BBQ is helpful to explore the beliefs of an individual about the inevitable consequences of LBP. The questionnaire contains 14 statements out of which 5 statements are used as distractors. The scoring is done on a five-point likert scale ranging from 1 (completely disagree) to 5 (completely agree). The scores of 9 statements are reversed and then summed to provide a total score ranging from 9 to 45. Low scores indicate negative beliefs of an individual towards LBP. The BBQ poses adequate internal consistency (Cronbach $\alpha=0.70$ ) and test-retest reliability (ICC $=0.87)$ [13]

Fig. 1: Flow of Participants.

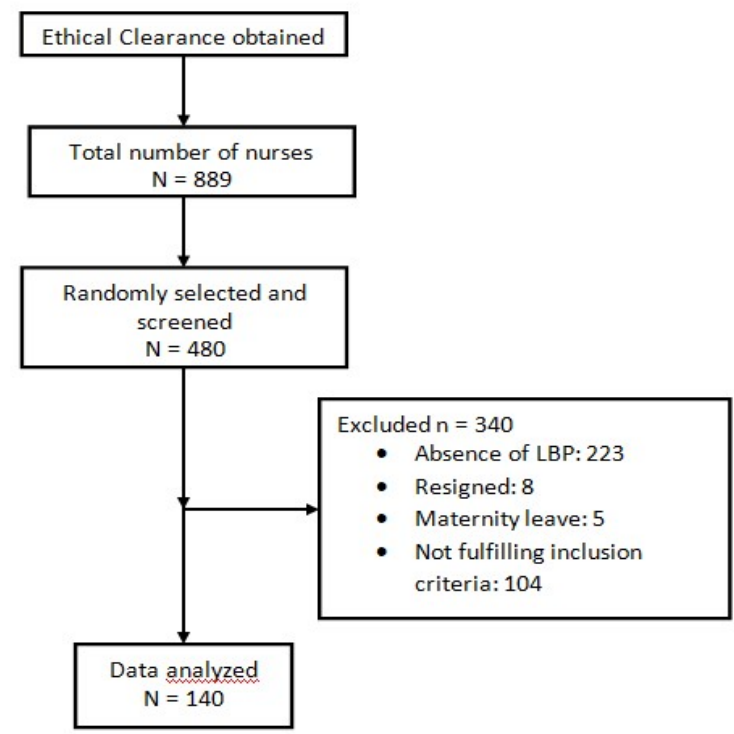

\section{RESULTS}

Analysis of data was done using Statistical Package for Social Sciences version 20. Categorical variables are described as frequencies and percentages.ODI scores were correlated with BBQ scores using Spearman's Rank correlation test. The Spearman's Rank correlation coefficient 'rho value' was used to evaluate correlation between the data. Statistical significance was determined by ' $p$ value'. A total of 480 nurses were screened, of them 140 nurses fulfilled the criteria of the study and their data was analyzed. The mean age of the participants was 30.76 years \pm 4 .39. The hours of duration at work were 47.54 hours \pm 13.66 and the years of total experience were 7.47 years \pm 4.02 .
Table 1: Professional characteristics of the participants $(\mathrm{N}=140)$.

\begin{tabular}{|c|l|c|c|}
\hline Variables & & $\mathbf{N}$ & Percent (\%) \\
\hline \multirow{3}{*}{ Designation } & Nursing supervisor & 2 & $1.40 \%$ \\
\cline { 2 - 4 } & Staff nurse & 126 & $90.00 \%$ \\
\cline { 2 - 4 } & Shift incharge & 6 & $4.30 \%$ \\
\cline { 2 - 4 } & Ward incharge & 6 & $4.30 \%$ \\
\hline \multirow{3}{*}{ area of work } & Operation theatre (ot) & 13 & $9.30 \%$ \\
\cline { 2 - 4 } & Out patient department & 19 & $13.60 \%$ \\
\cline { 2 - 4 } & Intensive care unit (icu) & 29 & $20.70 \%$ \\
\cline { 2 - 4 } & Ward & 79 & $56.40 \%$ \\
\hline \multirow{2}{*}{ Education } & Diploma & 119 & $85 \%$ \\
\cline { 2 - 4 } & Bsc. Nursing & 21 & $15 \%$ \\
\hline & Total & 140 & $100 \%$ \\
\hline
\end{tabular}

The table 1 shows that majority of the participants in the present study were staff nurses. The area of work of participants shows that most of the participants were working in the ward (56.4\%) and least percentage of participants was working in the OT (9.3\%). It was also found that majority of the participants have reported that they have pursued Diploma in Nursing $(85 \%)$ as highest level of education.

Normality test was performed; it was found that the data was non-parametric. Therefore, median, $1^{\text {st }}$ and $3^{\text {rd }}$ quartiles were considered. In ODI, the median score was $20,1^{\text {st }}$ and $3^{\text {rd }}$ quartiles were 16 and 26. Taking median into account, the results indicate that the nurses had minimal disability. For BBQ, the median score was 27, $1^{\text {st }}$ and $3^{\text {rd }}$ quartiles were 24 and 31 respectively. The $B B Q$ results indicate that the nurses had moderately positive beliefs.

Table 2: Correlation between ODI and BBQ.

\begin{tabular}{|c|c|c|}
\hline $\begin{array}{c}\text { Spearman's rho } \\
(\mathrm{n}=140)\end{array}$ & $\begin{array}{c}\text { Correlation coefficient } \\
\text { (rho value) }\end{array}$ & $\begin{array}{c}\text { Significance } \\
(\mathbf{p} \text { value) }\end{array}$ \\
\hline $\begin{array}{c}\text { Oswestry disability index } \\
\text { And back beliefs } \\
\text { questionnaire }\end{array}$ & -0.193 & 0.022 \\
\hline
\end{tabular}

The table 2 demonstrates the rho and $p$ value derived by correlating $\mathrm{ODI}$ values and $\mathrm{BBQ}$ values. As the data was non-parametric, Spearman's ranking correlation was done. The test shows that there is very weak negative correlation between ODI and BBQ.

Spearman's ranking correlation coefficient demonstrated that the rho value was -.193 and the $p$ value was .022 . The test demonstrates that there is very weak negative correlation between 
$O D I$ and $B B Q$. The results indicate that the beliefs of nurses did not influence their level of disability.

Graph 1: Scatter plot of ODI and BBQ values depicting a very weak negative correlation as shown by the trend line which is statistically significant $(p<.022)$.

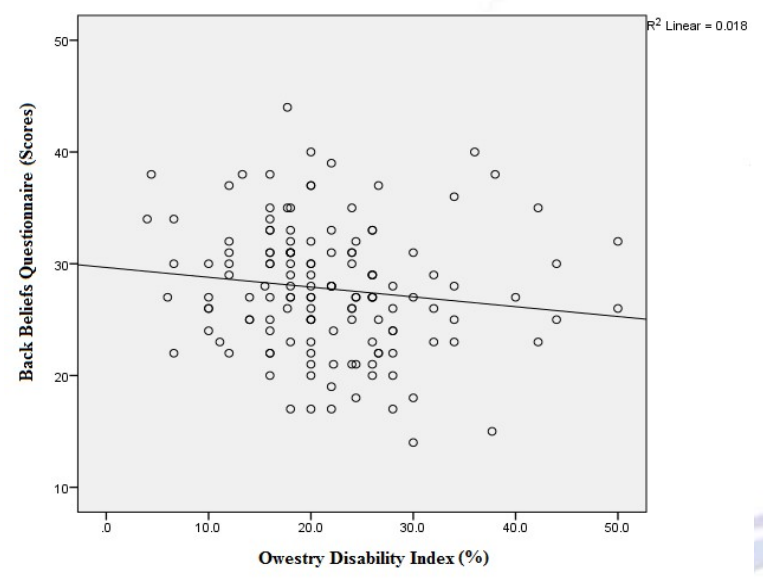

\section{DISCUSSION}

The purpose of the present study was to assess the functional disability and back pain beliefs among nurses with LBP. Furthermore, it was also to co-relate the scores of ODI and BBQ of nurses with LBP. Out of 480 participants, 140 had LBP and fulfilled inclusion criteria and their data were analyzed.

The LBP-induced functional disability was assessed by using ODI. The results indicated that the participants had minimal disability. The reason for this can be the ergonomic advises received by the nurses during induction and also the constant training being conducted at the hospital.

In addition to this, the beliefs of nurses towards LBP were assessed using BBQ. The results demonstrated that the beliefs of nurses towards their LBP were moderately positive. In the present study, as the nurses were having minimal disability, so their beliefs were positive. Moreover, the intensity of pain might have an impact on beliefs. The intensity of pain was low because of which the beliefs of the nurses were positive.

On analyzing the correlation between the ODI and BBQ scores, it was found that there is a very weak negative correlation between them. To our knowledge, correlation between back pain beliefs and functional disability among Indian nurses has not been studied. This is the first study to explore this correlation. There can be various reasons which contribute to the result. Firstly, the years of experience might have an impact on beliefs of nurses. With experience the nurses might have adapted to pain and found coping strategies which might have developed a better outlook towards the consequences of LBP. The nurses must have learnt proper patient handling [14]. This in turn would have helped them to continue their daily level of activities, hence encouraging them to actively participate in their work.

Secondly, being a part of health care setting the nurses may have acquired knowledge about LBP. This might have lead to better understanding about the nature of their pain. Nesto (2011) conducted a study on patients attending outpatient physiotherapy department in Malawi to identify their knowledge, attitudes and beliefs on the contributing factors of LBP. The authors found that participants were partially knowledgeable about LBP, and had negative attitudes and beliefs about LBP [15]. In a previous study it was stated that pain tolerance and disability were influenced by an individual's understanding and knowledge about the condition [16]. Therefore, knowledge can also be a contributing factor in nurses with LBP which was not assessed in the current study.

Lastly, physical activity is also an important factor which might have influenced the results of the present study. Physical activity performed during their leisure time was not assessed in the study. In a study conducted by Roupa et al. (2008), it was found that engaging in exercise and physical fitness reduces the risk of LBP. Additionally, involving in physical activity leads to healthier life style and improves psychosocial behavior [17]. The population in the present study might have engaged in exercises leading to positive beliefs and lower level of disability. All the above contributing factors might have influenced the result of the present study. Thereby, leading to a negative correlation between back pain beliefs and functional disability.

The results of the present study also imply positive beliefs of nurses towards LBP, which will prevent the chronicity of pain. This will lead to improved quality of life of nurses and enable them to work effectively. Despite the negative 
correlation derived from the present study, back program can be incorporated which should include educational class on ergonomics and back pain and exercises to improve the endurance of back muscles. Future studies can be conducted on back pain beliefs and its relation to knowledge, level of physical activity, stress among Indian nurses.

The present study had few limitations. Along with self-administered questionnaires, an objective tool to assess fitness level testing could have given a better outlook towards the study. The data of participants with minimal and moderate disability could have been evaluated separately.

\section{CONCLUSION}

The results of this study indicated that the nurses had minimal disability and moderately positive beliefs towards their LBP. Furthermore, it can be concluded that the beliefs of the nurses do not have an influence on their functional disability.

\section{ACKNOWLEDGEMENTS}

We acknowledge the constant support of our Head of Department, Prof. Savita Ravindra, Department of Physiotherapy, Ramaiah Medical College, Bangalore.

\section{ABBREVATIONS}

LBP - Low Back Pain

ODI - Oswestry Disability Index

BBQ - Back Beliefs Questionnaire

WMSD - Work-related Musculoskeletal Disorder

HCP - Health Care Professionals

OT - Operation Theatre

ICU - Intensive Care Unit

\section{Conflicts of interest: None}

\section{REFERENCES}

[1]. Yasobant S, Rajkumar P. Work-related musculoskeletal disorders among health care professionals: A cross-sectional assessment of risk factors in a tertiary hospital, India. Indian J Occup Environ Med. 2014;18(2):75-81.

[2]. del Pozo-Cruz B, Gusi N, Adsuar JC, del Pozo-Cruz J, Parraca JA, Hernandez-Mocholí M. Musculoskeletal fitness and health-related quality of life characteristics among sedentary office workers affected by sub-acute, non-specific low back pain: a cross-sectional study. Physiotherapy. 2013 Sep;99(3):194200.
[3]. M Emmanuel N, Ezhilarasu P. Low Back Pain among Nurses in a Tertiary Hospital, South India. Journal of Osteoporosis and Physical Activity [Internet]. 2016 [cited 2017 May 26];04(01). Available from: http://www.esciencecentral.org/journals/low-backpain-among-nurses-in-a-tertiary-hospital-southindia-2329-9509-1000161.php?aid=70682

[4]. Cilliers L, Maart S. Attitudes, knowledge and treatment of low back pain amongst nurses in the Eastern Cape, South Africa. African journal of primary health care \& family medicine [Internet]. 2013 [cited 2017 Apr 16];5(1). Available from: https:// www.ncbi.nlm.nih.gov/pmc/articles/PMC4502902/

[5]. Kane PP. Stress causing psychosomatic illness among nurses. Indian Journal of Occupational and Environmental Medicine. 2009 Jan 1;13(1):28.

[6]. Tan B-K, Smith AJ, O'Sullivan PB, Chen G, Burnett AF, Briggs AM. Low back pain beliefs are associated to age, location of work, education and pain-related disability in Chinese healthcare professionals working in China: a cross sectional survey. BMC Musculoskelet Disord. 2014 Jul 28;15:255.

[7]. Deyo RA, Tsui-Wu Y-J. Functional disability due to back pain. a population-based study indicating the importance of socioeconomic factors. Arthritis \& Rheumatology. 1987;30(11):1247-1253.

[8]. Dawson AP, McLennan SN, Schiller SD, Jull GA, Hodges PW, Stewart S. Interventions to prevent back pain and back injury in nurses: a systematic review. Occupational and Environmental Medicine. 2007 Jan 25;64(10):642-50.

[9]. Kennedy N, Healy J, O' Sullivan K. The Beliefs of Third-Level Healthcare Students towards Low-Back Pain. Pain Research and Treatment. $2014 \mathrm{Apr}$ 10;2014:e675915.

[10]. Vlaeyen J, Crombez G. Fear of Movement/(re)injury, Avoidance and Pain Disability in Chronic Low Back Pain Patients.1999; 4 (4):187-195.

[11]. Laleh S, Asra N, Pourhaji F, others. Chronic low back pain and disability among nurses: a cross sectional study from Bam, Iran. International Journal of Musculoskeletal Pain Prevention. 2016;1(1):29-33.

[12]. Vianin M. Psychometric properties and clinical usefulness of the Oswestry Disability Index. Journal of Chiropractic Medicine. 2008 Dec;7(4):161-3.

[13]. Symonds TL, Burton AK, Tillotson KM, Main CJ. Do attitudes and beliefs influence work loss due to low back trouble? Occupational Medicine. 1996; 46(1):25-32.

[14]. June KJ, Cho S-H. Low back pain and work-related factors among nurses in intensive care units: Back pain and work-related factors among ICU nurses. Journal of Clinical Nursing. 2011 Feb;20(3-4):47987.

[15]. Tarimo NS. KNOWLEDGE, ATTITUDES AND BELIEFS ON CONTRIBUTING FACTORS AMONG LOW BACK PAIN PATIENTS ATTENDING OUTPATIENT PHYSIOTHERAPY TREATMENT IN MALAWI [Internet]. Citeseer; 2011 [cited 2017 May 26]. Available from: http:/ citeseerx.ist.psu.edu/viewdoc/download? doi=10.1.1.952.7082\&rep=rep1\&type $=$ pdf 
[16]. Appelt CJ, Burant CJ, Siminoff LA, Kwoh CK, Ibrahim SA. Arthritis-specific health beliefs related to aging among older male patients with knee and/or hip osteoarthritis. The Journals of Gerontology Series A: Biological Sciences and Medical Sciences. 2007;62(2):184-190.
[17]. Zoe R. The problem of lower back pain in nursing staff and its effect on human activity. Health science journal [Internet]. 2008 [cited 2017 May 26]; Available from: http://www.hsj.gr/medicine/theproblem-of-lower-back-pain-in-nursing-staff-andits-effect-on-human-activity.php?aid=3656.

How to cite this article:

Hameeda Dharani, Soni S. RELATIONSHIP BETWEEN FUNCTIONAL

DISABILITY AND BELIEFS AMONG NURSES WITH LOW BACK PAIN. Int J

Physiother Res 2017;5(4):2253-2258. DOI: 10.16965/ijpr.2017.182 